\title{
THE TOXIC PROPERTIES OF DEMETON-METHYL ("METASYSTOX") AND SOME RELATED COMPOUNDS
}

\author{
BY \\ M. VANDEKAR* \\ From the Toxicology Research Unit, Medical Research Council Laboratories, Carshalton, Surrey
}

(RECEIVED FOR PUBLICATION NOVEMBER 24, 1957)

The active ingredients in commercial demetonmethyl ("metasystox") are the two isomers, 00-dimethyl 0-ethylthioethyl phosphorothionate (thionate isomer) and 00-dimethyl S-ethylthioethyl phosphorothiolate (thiolate isomer). By analogy with demeton (" systox"), which consists of a similar mixture of the 00-diethyl homologues and has been studied in plants by Heath, Park, Lickerish, and Edson (1953), and by Heath, Lane, and Park (1955), and in plants and animals by Fukuto, Metcalf, March, and Maxon (1955), it seemed likely that the action of demeton-methyl would be due mainly to the sulphoxide and sulphone of the thiolate, produced metabolically both in plants and animals. The demeton-methyl isomers, however, also undergo other reactions in water and on storage, giving small yields of sulphonium compounds of very high intravenous toxicity. The reactions involved are described by Heath and Vandekar (1957) and by Heath (1958) and are summarized here:

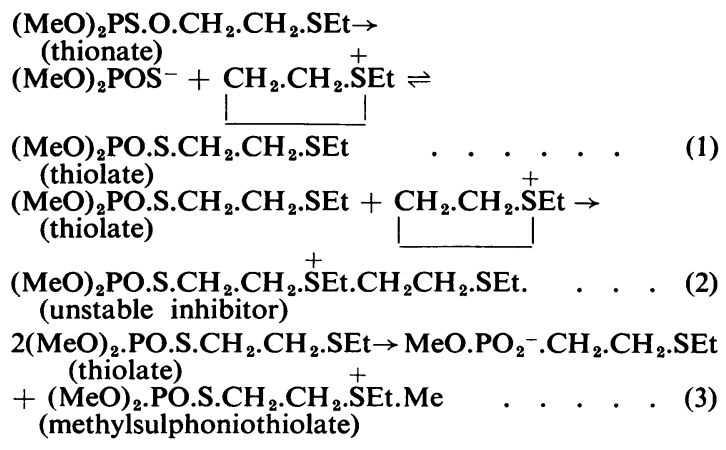

The yields of thiolate from the isomerization of the thionate (reaction 1) do not exceed $50 \%$ in water,

* Present address : Institute for Medical Research, Zagreb, Yugoslavia. as other reactions, giving inert products, take place.

In addition, the sulphoxide of the thiolate is partly converted to the thiolate on storage, though not apparently in solution, and then undergoes the reactions already described.

Some properties of the toxic compounds are given in Table 1. The thionate and the urstable inhibitor are both much less stable than the rest.

As a result of these properties and the reactions given, the demeton-methyl isomers show considerable increases in toxicity both in water and on storage undiluted.

In this paper toxic properties of commercial " metasystox" and of the aged (converted) samples of demeton-methyl isomers and their derivatives are recorded and results compared with those obtained for the purified compounds (Heath and Vandekar, 1957; Vandekar and Heath, 1957). The aim of such a comparison is to show how the toxicity data may vary if certain compounds are allowed to age by storage or if their toxicity is estimated at different times after dilution in water. Not only may the toxic dose change for certain compounds but the type and duration of symptoms produced after sublethal intravenous injection alter.

Chronic toxicity tests were carried out by feeding rats with different concentrations of two aged specimens of thiolate isomer and sulphoxide. For reasons given later it would appear that such converted compounds may play the most important role in producing any toxic hazard that may arise from the consumption of the food treated with "metasystox". The degree of the reduction of the brain and erythrocyte cholinesterase activity was recorded and results were compared with those obtained in chronic feeding experiments with demeton (" systox") (Barnes and Denz, 1954).

The results are recorded in some detail because they reveal further problems which may arise in 
assessing the toxicity of organo-phosphorus compounds with the property of inhibiting cholinesterase. The possibility of conversion and isomerization both before and after administration of these compounds to animals has been discussed before (Aldridge and Barnes, 1952), but in general this problem has received inadequate attention in the literature now growing up round toxicity studies on these compounds. These studies with demetonmethyl have revealed further examples of what may happen to some of these organo-phosphorus compounds.

\section{Materials and Methods}

Commercial " metasystox" was used in some experiments; it is stated by the makers to be a mixture of thionate and thiolate isomers in the proportion $70 / 30$, diluted $1: 1$ with an emulsifier. The short names and formulae of the compounds* under investigation are shown in Table 1. All compounds were stored in the dark and some of them in the cold and dilutions were prepared immediately before use. Special precautions were taken in assessing the toxicity of the specimens of thionate isomer in order to reduce as much as possible the interval between the time of preparing dilutions and administering them to the animal.

Acute Toxicity Tests.-These were carried out on male and female albino rats from the laboratory stock. There were no significant differences in the responses of the two sexes to the compounds studied. Animals were kept under observation until all symptoms disappeared and for at least 24 hours. For oral doses a solution in water or $10 \%$ ethanol was administered. For injections, solutions in either water, propylene glycol, or ethanol were used or the undiluted compound was given by a microsyringe. When solvents were used, volumes of injections were kept within $0 \cdot 1 \mathrm{ml} . / 100 \mathrm{~g}$. body weight in order to minimize any possible toxic effects from the solvent. The L.D.50 and $95 \%$ confidence limits were calculated by the method of Thompson and Weil (1952), using the tables for median-effective dose given by Weil (1952). This involves the use of four groups of four animals each with the dose levels related by a common factor.

Estimation of Recovery of Brain and Erythrocyte Cholinesterase Activity.-The organo-phosphorus compounds dissolved in saline were injected into the tail vein of male and female rats (200 to $250 \mathrm{~g}$.). The doses were close to the L.D.50 and invariably produced severe symptoms. At selected times animals were killed by coal gas. At death, blood ( 5 to $8 \mathrm{ml}$.) was collected into $0.2 \mathrm{ml}$. of $1 \%$ heparin from the vena cava, and the erythrocytes were washed twice with cold buffer. Brain was dissected out, washed in buffer, blotted dry, weighed, and suspended in cold buffer (approximate concentration $70 \mathrm{mg} . / \mathrm{ml}$.) using a homogenizer of the Folley and Watson type. Buffer solution contained $0.0357 \mathrm{M}$ $\mathrm{NaHCO}_{3}, 0 \cdot 164 \mathrm{M}-\mathrm{NaCl}$, and $0 \cdot 040 \mathrm{M}-\mathrm{MgCl}_{2}$ and was

* Kindly supplied by Messrs. Bayer of Leverkusen. freshly prepared from stock solutions and cooled to $5^{\circ} \mathrm{C}$. before use.

Cholinesterase Activity.-Estimations were carried out in the Warburg apparatus at $37^{\circ} \mathrm{C}$. with an atmosphere of $95 \% \mathrm{~N}_{2}+5 \% \mathrm{CO}_{2}$. Acetylcholine chloride was used as substrate with final concentration of $0.0138 \mathrm{M}$. One millilitre of brain suspension or the amount of washed erythrocytes corresponding to $0.5 \mathrm{ml}$. blood was generally used, but for highly inhibited samples $3 \mathrm{ml}$. of brain suspension or $1.5 \mathrm{ml}$. of blood was taken. Gassing and equilibration time in the bath did not exceed 15 minutes.

Anticholinesterase Activity.-The anticholinesterase activity of the specimens was determined with sheep erythrocyte cholinesterase for 30 minutes at $37^{\circ} \mathrm{C}$., followed by the determination of the cholinesterase activity remaining (Aldridge, 1950).

The return of brain and erythrocyte cholinesterase activity was measured in vitro after selected times of incubation at $37^{\circ} \mathrm{C}$. (Aldridge, 1953).

Persistence of Inhibitory Power of Serum.-The persistence of the inhibitory power of serum in rats was estimated at selected intervals after single intravenous injections when animals were killed by coal gas and blood collected as described above. Serum was separated and $2 \mathrm{ml}$. of serum was incubated with normal rat erythrocytes for one hour at $37^{\circ} \mathrm{C}$. The erythrocytes were then washed twice with buffer and cholinesterase activity was estimated as above. The results are expressed as a percentage of the activity of erythrocytes treated in the same way with serum obtained from normal rats.

Chronic Feeding Experiments.-For the chronic feeding experiments solutions of the aged specimens of the thiolate isomer and sulphoxide were made up in arachis oil and added at the rate of $10 \mathrm{ml} . / \mathrm{kg}$. of powdered rat diet (M.R.C. diet 41). A weighed quantity was given daily to each cage. The food remaining next day was waighed so that the daily intake could be estimated. Animal weights were recorded regularly. All surviving animals were killed after six months by coal gas. Tissues for histology were fixed in Helly's fluid and stained by haematoxylin and eosin. Cholinesterase determinations were done on brain suspensions and washed erythrocytes as described above. The inhibitory power of serum was estimated; serum was incubated with normal erythrocytes for two hours instead of one hour as described above.

\section{Results}

Comparison between Aged and Purified Compounds.- Both thionate and thiolate isomers and the sulphoxide (Table 1) showed a significant increase in intravenous toxicity on ageing.

Different specimens of the same compounds when tested on their arrival already showed different L.D.50 values and after storage for several months they showed a further increase in toxicity. The toxicity increased similarly in the samples prepared or purified in our laboratory if stored for several months at room temperature. This is illustrated in Table 2 for one of the compounds in question, 
TABLE 1

DATA ON CHEMICAI AND BIOLOGICAL PROPERTIES OF ISOMERS, METABOLITES AND TRANSFORMATION PRODUCTS OF DEMETON-METHYL (TAKEN FROM HEATH AND VANDEKAR, 1957, AND HEATH, 1958)

\begin{tabular}{|c|c|c|c|c|}
\hline Short Name & \multicolumn{3}{|c|}{ Formula } & Half Life in Wat \\
\hline Thionate & \multicolumn{3}{|c|}{$(\mathrm{MeO})_{2}$ PS.O. $\mathrm{CH}_{2} . \mathrm{CH}_{2} . \mathrm{SEt}$} & $\begin{array}{r}9.2 \mathrm{~min} \text {. at } 37^{\circ} \\
46 \mathrm{~min} \text {. at } 21.8^{\circ}\end{array}$ \\
\hline Thiolate & \multicolumn{3}{|c|}{$(\mathrm{MeO})_{2} \mathrm{PO} . \mathrm{S} . \mathrm{CH}_{2} \cdot \mathrm{CH}_{2} \cdot \mathrm{SEt}$} & 11 days at $37^{\circ} \mathrm{C}$ \\
\hline Sulphoxide & \multicolumn{3}{|c|}{$(\mathrm{MeO})_{2}$ PO.S. $\mathrm{CH}_{2} \cdot \mathrm{CH}_{2}$. SO.Et } & 22 days at $37^{\circ} \mathrm{C}$ \\
\hline Sulphone & \multicolumn{3}{|c|}{$(\mathrm{MeO})_{2} \mathrm{PO} \cdot \mathrm{S} \cdot \mathrm{CH}_{2} \cdot \mathrm{CH}_{2} \cdot \mathrm{SO}_{2} \cdot \mathrm{Et}$} & 18.5 days at $37^{\circ}$ \\
\hline $\begin{array}{l}\text { Methylsulphonio- } \\
\text { thiolate }\end{array}$ & \multicolumn{3}{|c|}{$(\mathrm{MeO})_{2}$ PO.S. $\mathrm{CH}_{2} \cdot \mathrm{CH}_{2} \cdot \stackrel{+}{\mathrm{S} E t M e}$} & 13.4 days at $37^{\circ}$ \\
\hline Unstable Inhibitor & \multicolumn{3}{|c|}{$(\mathrm{MeO})_{2}$ PO.S. $\mathrm{CH}_{2} \cdot \mathrm{CH}_{2} \cdot \stackrel{+}{\mathrm{S} E t} \cdot \mathrm{CH}_{2} \cdot \mathrm{CH}_{2} \cdot \mathrm{SEt}$} & $100 \mathrm{~min}$. at $37^{\circ} \mathrm{C}$ \\
\hline \multicolumn{5}{|c|}{$\begin{array}{c}+95 \% \text { confidence limits are given below L.D. } \\
\text { at which all four survived so that no limits could } \\
*=\text { Male rats. Where the sensitivity of the } \\
\text { TABLE } 2\end{array}$} \\
\hline \multirow{2}{*}{\multicolumn{2}{|c|}{ Specimen* }} & Time of & \multicolumn{2}{|c|}{ L.D.50 (mg./kg.) } \\
\hline & & Determination & Intravenous & Oral \\
\hline $\begin{array}{l}\text { No. } 3 \\
\text { No. }\end{array}$ & & $\begin{array}{l}\text { On arrival } \\
\text { Seven months } \\
\text { later } \\
\text { On arrival } \\
\text { Three-and-a-half } \\
\text { months later } \\
\text { On arrival } \\
\text { Freshly prepared } \\
\text { Six-and-a-half } \\
\text { months later }\end{array}$ & $\begin{array}{c}32 \cdot 7 q \\
(23 \cdot 1-46 \cdot 3) \\
4 \cdot 7 \delta \\
(-) \\
28 \cdot 2 \% \\
(23 \cdot 0-34 \cdot 2) \\
8 \cdot 4 \delta \\
(-) \\
2 \cdot 0 \delta \\
(1 \cdot 6-2 \cdot 5) \\
47 \cdot 2 \delta \\
(-) \\
15 \cdot 4 \sigma^{*} \\
(12 \cdot 9-18 \cdot 3)\end{array}$ & $\begin{array}{c}- \\
- \\
84 \cdot 1 \% \\
(59 \cdot 5-119) \\
- \\
80 \cdot 0 \% \\
(54 \cdot 8-117) \\
64 \cdot 6 \% \\
(54 \cdot 4-76 \cdot 8) \\
-\end{array}$ \\
\hline
\end{tabular}

*Specimens 1, 2, and 3 were obtained from Messrs. Bayer of Leverkusen (the date of production unknown). Specimen No. 4 was prepared in our laboratory (Heath and Vandekar, 1957).

sulphoxide. The sulphone, on the other hand, did not show any increase in toxicity.

Toxicity data, summarized in Table 1, where aged specimens are compared with purified compounds, show that the increase in toxicity is much more obvious when the intravenous toxicities are compared, the oral toxicities changing less markedly. Anticholinesterase activity in vitro parallels the high increase in intravenous toxicity.

On intravenous injection all the specimens except the purified thionate isomer produced typical signs of poisoning from cholinesterase inhibition, but there was a difference in the speed of onset and the duration of poisoning produced by the purified and the aged specimens. Pure specimens had a relatively low toxicity with a delayed onset and prolonged duration of the signs of poisoning. Their toxicity increased progressively on ageing with a more rapid onset and shorter duration of poisoning.

The high intravenous toxicity of an aged specimen will obviously depend on the presence of even the smallest amounts of the sulphonium compounds, which Heath and Vandekar (1957) showed were formed in those compounds which increased in toxicity on storage. In this work no attempt was made to distinguish between the methyl sulphoniothiolate and the unstable cholinesterase inhibitor. As shown in Table 1 the toxic characteristics of the aged thiolate isomer and the aged sulphoxide have approached those of the sulphonium derivatives. On the other hand, when aged specimens are tested orally, the presence of sulphonium derivatives is much less crucial because of their relatively low oral toxicity.

The intravenous injection of sublethal doses of purified thionate isomer produced a moderate anaesthetic effect. A lethal dose produced deep anaesthesia lasting for $\mathbf{2 0}$ minutes or more. Animals recovered slowly from anaesthesia but haemorrhagic pulmonary oedema developed and animals died from respiratory failure without showing typical 
FIG. 1.-Cholinesterase activity of serum after single sublethal intravenous injection into male rats of an aged specimen of thiolate isomer (specimen No. 6) $(O)$ and purified thiolate isomer (Q). Each point represents one rat.

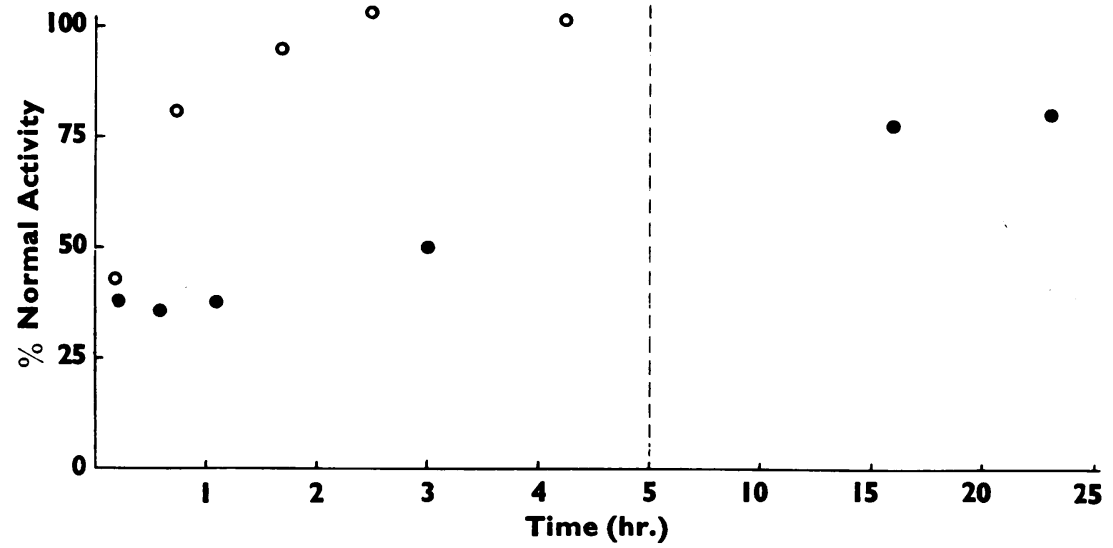

cholinergic symptoms. A slight anaesthetic effect was observed after intravenous injection of sublethal doses of purified thiolate isomer (Vandekar, 1957). Animals showed moderate brief incoordination followed by an interval of about 10 minutes when no obvious symptoms were present. Only then did typical cholinergic symptoms develop. When aged and more toxic specimens of thionate and thiolate isomers were injected intravenously only cholinergic symptoms were observed.

The effect of the persistence of the inhibitor in the body on the duration of symptoms and on the reactivation of cholinesterase in vivo has been shown recently (Vandekar and Heath, 1957) by a comparison of different dimethyl phosphate esters. Similar results have been obtained when the persistence of inhibitor in blood and the reactivation of erythrocytes were compared after sublethal intravenous injections of aged and purified specimens of thiolate isomer. The aged compound did not persist in the blood, and the activity of most of the inhibited erythrocyte cholinesterase returned rapidly. The purified compound, on the other hand, persisted in the blood for several hours and produced irreversible inhibition of most of the enzyme (Figs. 1 and 2). There was a further distinction between the aged and purified sample. While the purified thiolate isomer produced a considerable inhibition of brain cholinesterase, the aged sample inhibited the same enzyme only slightly (Fig. 2).

Effect of Dilution with Water.-Both thionate and thiolate isomers showed a rapid increase in intravenous toxicity when mixed with water. This is due to the formation of the toxic sulphonium derivatives at rates controlled by the concentration of the isomers

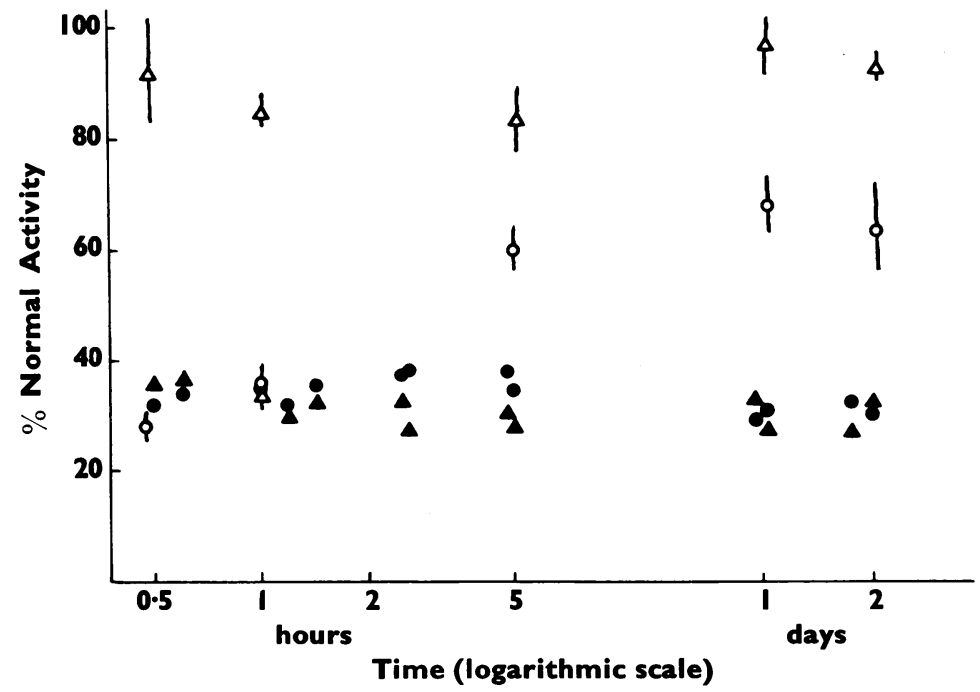

FIG. 2.-A comparison of the brain $(\Delta \Delta)$ and erythrocyte $(O \bigcirc)$ cholinesterase activity of rats at intervals up to two days after a single sublethal intravenous injection of:

(1) $1.2 \mathrm{mg} . / \mathrm{kg}$. of an aged specimen of the thiolate isomer (mean of four to six rats with $95 \%$ confidence limits);

(2) $50 \mathrm{mg} . / \mathrm{kg}$. of a purified specimen of the thiolate isomer (single rats);

Contrast the severe and sustained depression of brain cholinesterase activity after the purified specimen with the absence of inhibition in the brain after the aged specimen. 
and the temperature (Heath and Vandekar, 1957). Table 3 shows differences in intravenous toxicities obtained before and after conversion in water of both thionate and thiolate isomers. The changes in toxicity after dilution in water were studied with an aged specimen of thionate isomer (specimen No. 5). A rapid increase in intravenous toxicity was observed when a suspension of $1 \mathrm{mg}$. $/ \mathrm{ml}$. was left at room temperature (Fig. 3). The maximum toxicity (about 40 times higher than the original one) was found about four to eight hours after dilution; after 24 hours the toxicity decreased slowly, presumably as a result of hydrolysis of the unstable inhibitor (Heath, 1958). The rate of increase in the toxicity of the same specimen was rapid in $50 \%$ alcohol, methanol, or acetone, but was slowed if kept at $0^{\circ} \mathrm{C}$. or if the dilution was increased.

TABLE 3

INCREASE IN INTRAVENOUS TOXICITY TO RATS OF INHIONATE AND THIOLATE ISOMERS AFTER MIXING WITH WATER

\begin{tabular}{|c|c|c|}
\hline Compound & Injected & $\underset{\text { (mg./kg.) }}{\text { Intravenous L.D.50 }}$ \\
\hline Thionate isomer & $\begin{array}{l}\text { Undiluted (by microsyringe) } \\
\text { Diluted with water } \\
(1 \mathrm{mg} . / \mathrm{ml} \text {.) and left for } \\
75 \mathrm{~min} \text {. at } 35^{\circ} \mathrm{C} \text {. }\end{array}$ & $\begin{array}{r}216 \cdot 2 \\
2.5\end{array}$ \\
\hline Thiolate isomer & $\begin{array}{l}\text { Undiluted (by microsyringe) } \\
\text { Diluted with water } \\
(10 \mathrm{mg} . / \mathrm{ml} \text {.) and left for } \\
24 \mathrm{hr} \text { at } 35^{\circ} \mathrm{C} \text {. }\end{array}$ & $\begin{array}{c}64 \cdot 6 \\
2 .\end{array}$ \\
\hline
\end{tabular}

The increase in the oral toxicity of both thionate and thiolate isomers after mixing with water was much less marked.
Neither sulphoxide nor sulphone showed any increase in the intravenous toxicity on storage in $1 \%$ aqueous solution for one day at room temperature.

Commercial "Metasystox".- In some preliminary experiments commercial "metasystox" was used. Injected as an aqueous solution (10 mg. $/ \mathrm{ml}$.) intravenously in male rats, severe symptoms were produced in animals at $10 \mathrm{mg} . / \mathrm{kg}$. and death occurred in all injected animals at $15 \mathrm{mg} . / \mathrm{kg}$. The intravenous toxicity of the aqueous solution was considerably increased when left at room temperature. A freshly prepared solution with an L.D.50 of about $12 \mathrm{mg}$. $/ \mathrm{kg}$. had an L.D.50 of $1(0.5$ to 2.0$) \mathrm{mg}$. $/ \mathrm{kg}$. after two hours.

Oral toxicity was determined both in fed and fasted female rats. The L.D. 50 value was $226 \mathrm{mg}$. $/ \mathrm{kg}$. and $113 \mathrm{mg} . / \mathrm{kg}$. respectively. Death was delayed in fed as compared with fasted rats receiving the same amounts of the freshly prepared solution (Table 4).

\section{TABLE 4}

ONSET OF DEATH IN FED AND FASTED FEMALE RATS AFTER ORAL ADMINISTRATION OF FRESH AND TWOHOUR-OLD AQUEOUS SOLUTION OF COMMERCIAL

\begin{tabular}{|c|c|c|c|}
\hline $\begin{array}{c}\text { Dose } \\
\text { (mg./kg.) }\end{array}$ & Rats & Fresh Solution & $\begin{array}{l}\text { Two-hour-old } \\
\text { Solution }\end{array}$ \\
\hline $\begin{array}{l}320 \\
160\end{array}$ & $\begin{array}{l}\text { Fed } \\
\text { Fasted } \\
\text { Fed } \\
\text { Fasted }\end{array}$ & $\begin{array}{l}\text { Death in } 3 \frac{1}{2} \text { to } 5 \text { hours } \\
\text { Death in } 30 \text { to } 40 \mathrm{~min} \text {. } \\
\text { Survived } \\
\text { Death in } 50 \text { to } 60 \mathrm{~min} \text {. }\end{array}$ & $\begin{array}{l}\text { Death in } 20 \text { to } 40 \mathrm{~min} \text {. } \\
\text { Death in about } 15 \mathrm{~min} \text {. } \\
\text { Death in } 40 \text { to } 60 \mathrm{~min} \text {. } \\
\text { Death in } 30 \text { to } 40 \mathrm{~min} \text {. }\end{array}$ \\
\hline
\end{tabular}

An increase was found in the oral toxicity of the aqueous solution left for several hours at room 
temperature, but it was not so pronounced as that observed in the intravenous toxicity described above. The survival time was considerably shorter when a solution that had been allowed to stand for two hours was administered (Table 4). This change in the toxic properties of "metasystox" solution in water may be explained on the basis of the observations with the purified isolated isomers (Heath and Vandekar, 1957) and aged specimens described above (see Fig. 3).

\section{Chronic Toxicity Tests}

Aged Specimen of Thiolate Isomer.-Four groups of six male albino rats were fed diets containing $0,50,100$, and 200 p.p.m. of the aged specimen of thiolate isomer (specimen No. 6) for six months. Only the rats on 200 p.p.m. showed signs of poisoning. Slight tremors and fasciculations were observed occasionally within the first five weeks and one animal died during the fourth week. After the fifth week no further signs of this type were observed in spite of continued ingestion of the diet. One incidental death occurred among the control animals during the sixteenth week.

During the last month of the experiment dryness and scaliness of the tip of the tail was observed in three rats on 200 p.p.m. and in three rats on 100 p.p.m. At the beginning the tips were sore and a tendency to bleed was observed if the scaly surface was flaked off. Later the tips became completely dry, insensitive, and lacking flexibility. This change was progressing gradually and was more pronounced in the rats given 200 p.p.m. (Fig. 4).

Growth curves are given in Fig. 5a, and show that rats on 100 and 200 p.p.m. were affected. Rats on 50 p.p.m. showed, on the contrary, better growth than controls.

The daily food intake of the rats was measured throughout the experiment and the mean values for the first two periods of three weeks and the next four periods of five weeks are given in Fig. 6a. The food intake was somewhat greater in all experimental animals than in the controls during the whole experiment, but this difference was more pronounced in the first 16 weeks. The greatest consumption of food was recorded in rats on 100 p.p.m. In spite of the high food intake the rats on 100 p.p.m. remained lighter than controls and much lighter than rats on 50 p.p.m. (Fig. 5a).

The animals appeared normal at necropsy. The liver, kidney, and adrenals were examined histologically. No pathological changes attributable to the action of thiolate isomer or related compounds could be detected.

Both brain and erythrocyte cholinesterase activities

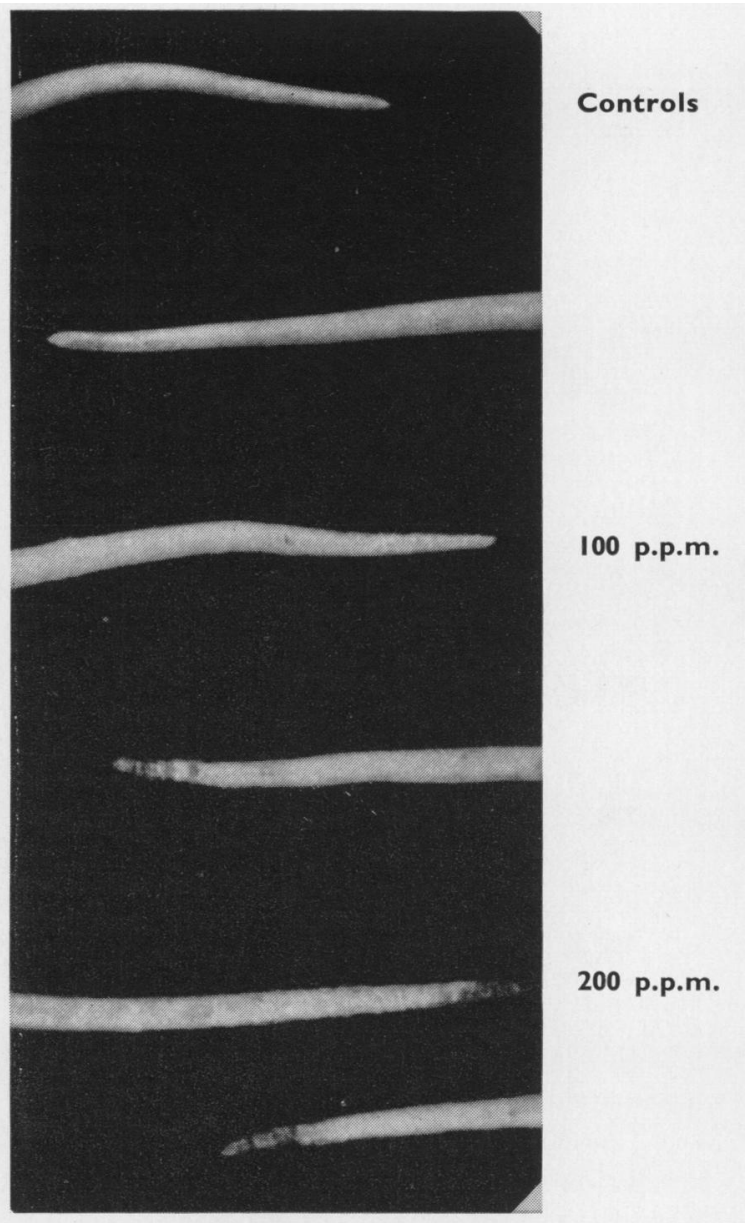

FIG. 4.-Tails of rats showing dryness and scaliness in those fed diets containing the aged specimen of thiolate isomer (specimen No. 6) for six months compared with two controls.

were considerably inhibited in rats on all levels of the inhibitor, showing less than $10 \%$ activity at 200 p.p.m. (Fig. 7a and b). In a certain number of samples the return of brain and erythrocyte cholinesterase activity was measured in vitro after selected times of incubation at $37^{\circ} \mathrm{C}$. The results obtained indicated that more than $90 \%$ of inhibition was irreversible.

The inhibitory power of the serum was estimated and results are given in Fig. 8.

Aged Specimens of Sulphoxide. - Twenty-four male albino rats divided into four groups of six were given $0,50,100$, and 200 p.p.m. of the aged specimen of sulphoxide (specimen No. 2) in their diet for six months. The rats on 100 and 200 p.p.m. showed slight tremor and were not as healthy as normal 


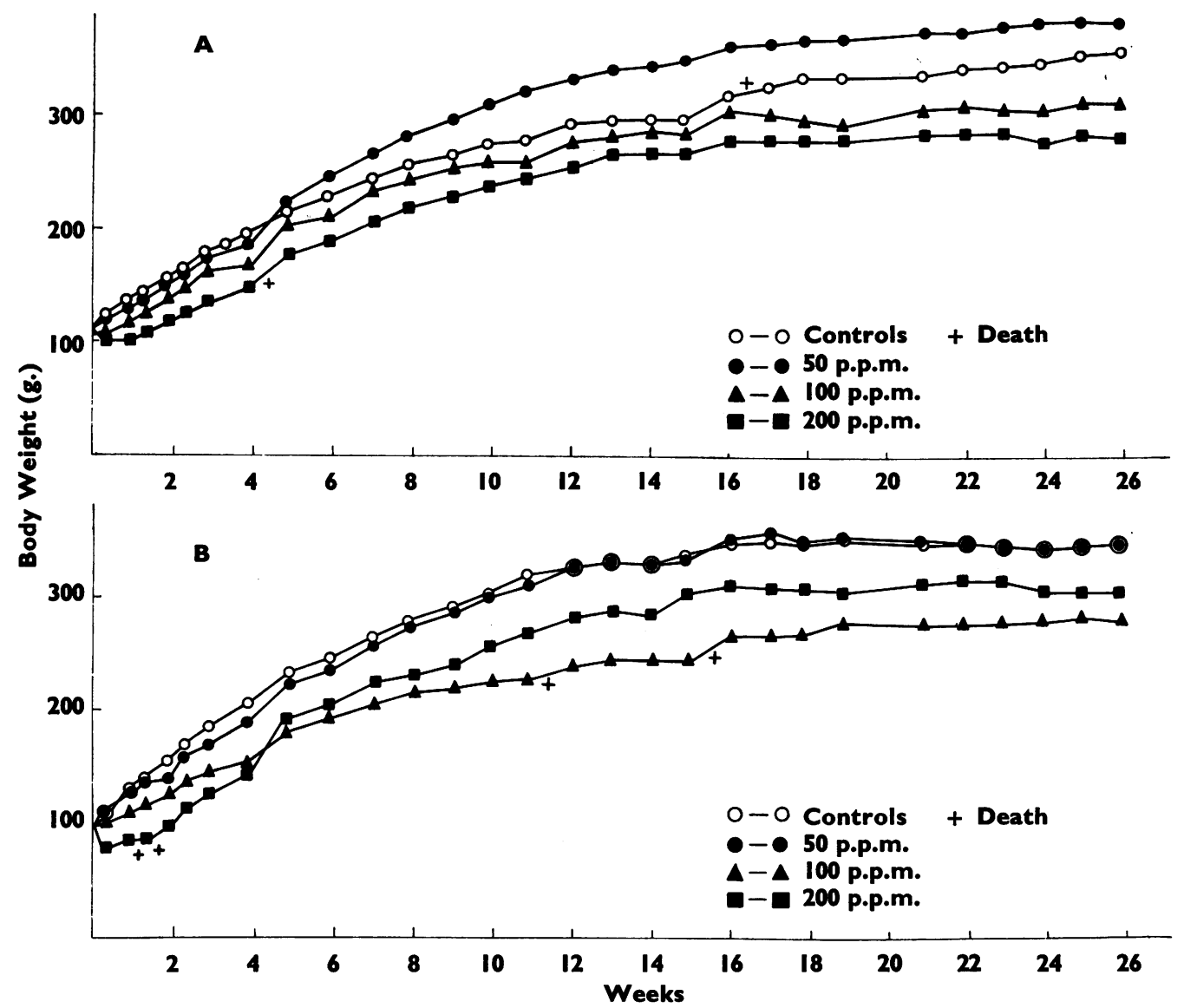

FIG. 5.-Weights of male rats on diets containing (A) aged thiolate isomer (specimen No. 6) and (B) aged sulphoxide (specimen No. 2)
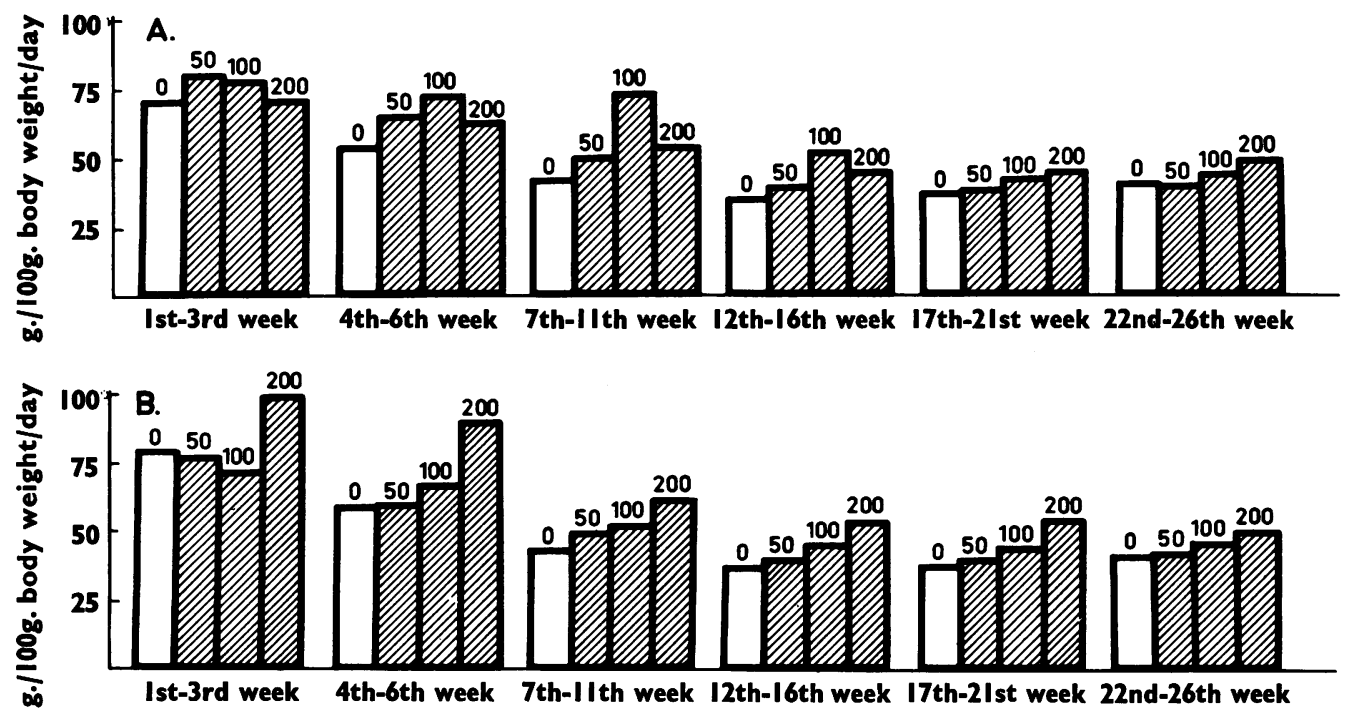

FIG. 6.-The daily food intake of rats on diets containing (A) aged thiolate isomer (specimen No. 6) and (B), aged sulphoxide (specimen No. 2). Each column is the mean daily intake for fixed periods of time expressed as g. of diet per $100 \mathrm{~g}$. body weight. 

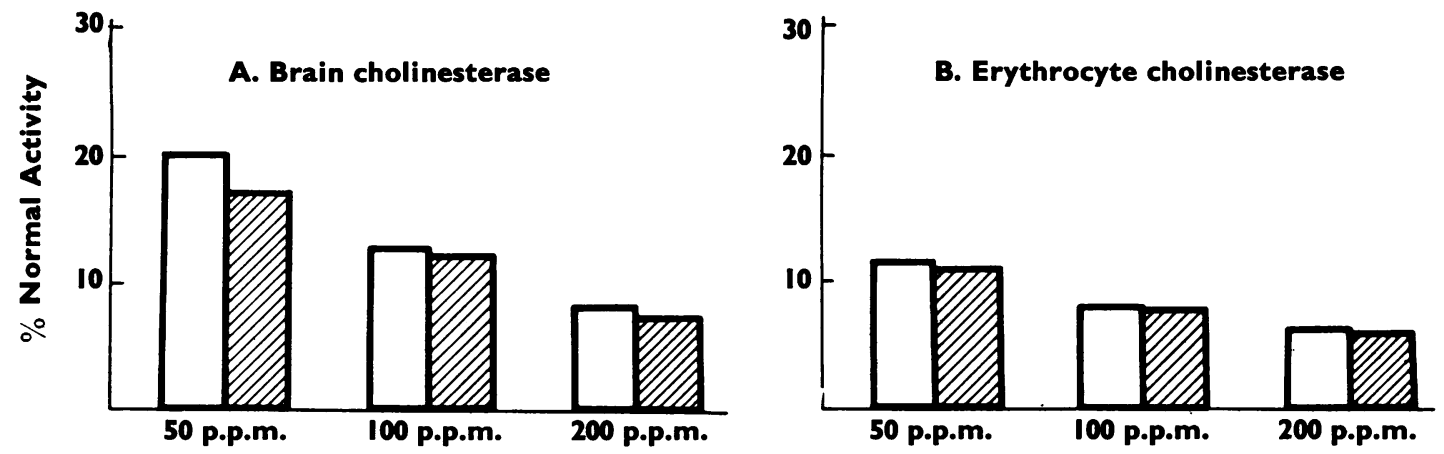

Fig. 7.-Cholinesterase activity of (A) brain and (B) red cells of male rats fed for six months on diets containing aged thiolate isomer (specimen No. 6) (white) and aged sulphoxide (specimen No. 2) (hatched). Each bar represents the mean of four to six rats.

during the first three weeks and two rats on 200 p.p.m. died during the second week of the experiment. After the first three weeks no signs indicative of cholinergic drug poisoning were observed in any group. Two incidental deaths occurred in the rats on 100 p.p.m. during the eleventh and fifteenth weeks.

Growth curves are given in Fig. 5b, and show that mean weights of rats on 50 p.p.m. did not differ from controls. The rats on 100 and 200 p.p.m. were affected, the latter more severely during the first month though thereafter the four surviving animals on 200 p.p.m. showed better growth than the rats on 100 p.p.m.

Means of food intake per $100 \mathrm{~g}$. body weight for definite periods during the experiment (Fig. 6b) show that the food consumption in the rats on

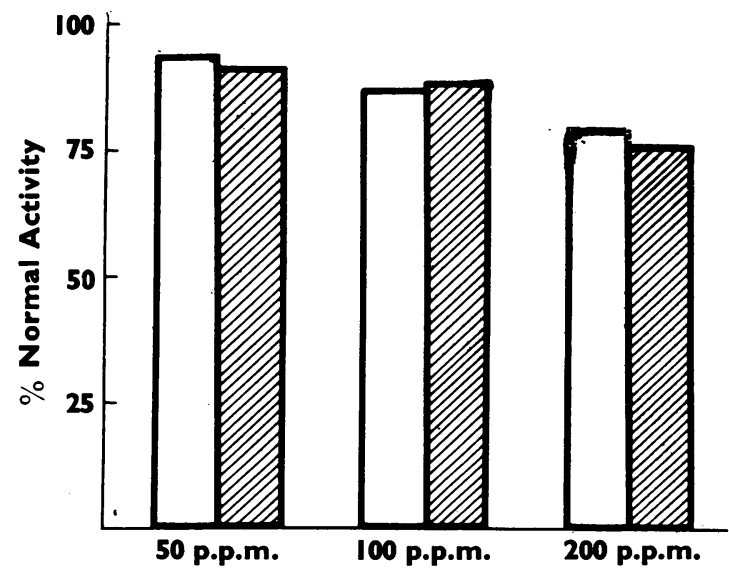

FIG. 8.-The inhibitory power of serum in male rats fed diets containing aged thiolate isomer (specimen No. 6) (white) and aged sulphoxide (specimen No. 2) (hatched). Each bar represents the mean of four rats. The serum was incubated at $37^{\circ} \mathrm{C}$ with normal erythrocytes and, after washing, activity of erythrocyte cholinesterase estimated.
200 p.p.m. was greater than in controls, and this difference was more pronounced in the first half of the experiment. In spite of the larger food intake the rats on 200 p.p.m. remained lighter than controls (Fig. 5b).

No pathological changes attributable to the action of sulphoxide or related compounds could be detected at necropsy or by histological examination of the liver, kidney, and adrenals.

The mean values for brain and blood cholinesterase activity after six months' feeding (Fig. 7a and b) show that they both were strongly inhibited at all three levels in the diet. At 200 p.p.m. less than $10 \%$ cholinesterase activity in brain and washed erythrocytes was found. The return of brain and erythrocyte cholinesterase was measured in vitro in several samples incubated at $37^{\circ} \mathrm{C}$. The results indicated that more than $90 \%$ of inhibition was irreversible.

The results of the estimation of anticholinesterase activity of serum are given in Fig. 8, showing that more than $20 \%$ of inhibition of erythrocyte cholinesterase was produced with the serum obtained from the rats on 200 p.p.m.

\section{Discussion}

It was shown by Heath et al. (1953) and Wirth (1953) that the thiolate isomer is the more toxic isomer in commercial "systox". Experiments with isolated dimethyl analogues (" metasystox " isomers) and related compounds showed that the thiolate isomer is more toxic than the thionate isomer, both showing relatively low toxicity when purified. It was also found that both isomers increased in toxicity on storage (or in water) by the formation of highly toxic sulphonium derivatives (Heath and Vandekar, 1957; Heath, 1957). The relatively high toxicity of the commercial " metasystox" product which was studied is consistent with the presence of 
the very toxic sulphonium derivatives: other toxic impurities cannot be excluded.

A comparison of the aged and purified compounds revealed marked differences not only in the degree of toxicity but also in the type, onset, and duration of symptoms produced, these differences being much more pronounced after intravenous administration. Thus, while the purified thionate isomer in large doses produced anaesthesia and haemorrhagic pulmonary oedema with no cholinergic symptoms, and the purified thiolate isomer produced a slight anaesthetic effect followed by cholinergic symptoms, the aged specimens of both thionate and thiolate isomers in very small doses produced cholinergic symptoms only. Similar anaesthetic effects have been observed with other organo-phosphorus compounds with little or no anticholinesterase activity (Vandekar, 1957).

When sublethal single doses of the purified thiolate isomer or purified sulphoxide were injected intravenously prolonged symptoms we:e induced. The inhibitor was found to persist in the blood for several hours producing an almost complete irreversible inhibition of cholinesterase. On storage the toxic properties of the thiolate isomer and sulphoxide changed markedly and came to resemble those of the non-persistent dimethyl phosphate esters (Vandekar and Heath, 1957). Thus, the aged specimen of thiolate isomer produced symptoms of short duration and did not persist in the blood. Most of the inhibited erythrocyte cholinesterase recovered its activity rapidly and no significant inhibition of brain cholinesterase was produced, all the findings being similar to those obtained with sulphoniothiolate (Vandekar and Heath, 1957). This effect of ageing should also be borne in mind when chronic toxicity tests with purified (non-converted) specimens are planned.

A considerable increase was found in the toxicity of commercial " metasystox" after mixing it with water. As in the experiments with purified isomers (Heath and Vandekar, 1957), experiments with aged thionate and thiolate isomers showed that a rapid increase in intravenous toxicity followed the mixing with water. The change in oral toxicity was, however, much less pronounced. The fact that toxicity can be considerably increased either on storage or within the first few minutes after mixing with water can easily lead to difficulties in measuring the L.D.50. Thus one more problem in the assessment of the toxicity of organo-phosphorus insecticides may well be added to those already discussed by Aldridge and Barnes (1952).

Purified compounds showed relatively small differences between intravenous and oral L.D.50 values, whereas aged specimens or solutions in water as well as commercial " metasystox" showed a marked difference between intravenous and oral toxicities. This appears to be due to the presence of certain amounts of toxic sulphonium derivatives in aged or converted specimens. Methyl sulphonio-thiolate isolated by Heath and Vandekar (1957) showed a ratio of the intravenous to oral L.D.50 of about $1: 100$. Its relatively low oral toxicity may be partly due to the ionic charge which interferes with absorption. Other experiments with slow intravenous infusion of certain dimethyl phosphate esters showing a pronounced difference between intravenous and oral toxicity (Vandekar, unpublished results)* suggested that such a difference was due largely to variations in the rates of entry into general circulation. When the aged thiolate isomer (specimen No. 6) was examined in this way, a decrease in the rate of infusion from $4.6 \mathrm{mg}$. $/ \mathrm{kg}$./ hour to $3 \mathrm{mg} . / \mathrm{kg}$./ hour resulted in a remarkable increase of tolerance from $1.8 \mathrm{mg}$. $/ \mathrm{kg}$. to $25.2 \mathrm{mg}$. $/ \mathrm{kg}$. It appears, therefore, that the higher values for the oral L.D.50 of both the commercial preparation and the individual aged or converted specimens are largely due to the "reducing-valve" action of the gastro-intestinal tract providing time for the body to take advantage of such defensive mechanisms as (a) reversal of inhibited enzyme (Aldridge, 1953); (b) the removal of the toxic sulphonium derivative either by demethylation to a less powerful inhibitor or by hydrolysis of inhibitor to non-toxic ionic products; and $(c)$ elimination of the inhibitor through the kidney.

The fact that the drug first enters the portal system increases the opportunity for possible metabolism to take place in the liver. The greater sensitivity of fasted compared with fed rats given commercial "metasystox" orally also indicates the importance of the rate of absorption in determining toxicity. The comparison between intravenous and oral L.D. 50 values of converted specimens (Tables 1 and 2) indicates that a rapid introduction of the drug into the body, e.g., intravenous injection, is necessary in order to reveal the change in the toxic properties of these compounds when stored or diluted with water.

Mühlmann and Tietz (1956) have suggested that two toxic transformation products, the sulphoxide and sulphone, are formed in the plant sprayed with 32P-labelled thiolate isomer of "metasystox". The history of the commercial "metasystox" product from the factory to its degradation in the crop

*The effects of different rates of infusion into rats' jugular veins have been studied with certain cholinesterase inhibitors, and the results will be discussed in more detail elsewhere. 
reveals a very large number of factors which may affect its toxicity. This has already been discussed by Heath and Vandekar (1957). Because of their rapid conversion to other products, the thionate and thiolate isomers per se will have little importance as residues in treated crops. Any hazard that might arise would be from the presence of their more toxic oxidative and sulphonium derivatives. The aged specimens of thiolate isomer (specimen No. 6) and sulphoxide (specimen No. 2), both containing some of these derivatives, were used in the long-term feeding experiments. The aged thiolate isomer, although much more toxic intravenously, when given to the animals regularly in the diet appeared to be somewhat less toxic than the aged sulphoxide. This greater toxicity of the sulphoxide was also seen in the acute oral toxicities. The degree of inhibition of erythrocyte and brain cholinesterase was proportional to the levels of the inhibitor mixed in the diet and was similar for both specimens. This depression of cholinesterase activity was considerable, though the animals in the later stages of experiments showed no signs of poisoning by an anticholinesterase agent. Similar observations were recorded by Barnes and Denz (1954) in rats fed demeton ("systox"). The observation that defective growth at the higher levels of feeding was associated with a higher food intake had also been noted in the case of demeton but not in the case of schradan (Barnes and Denz, 1954). This suggests that demeton-methyl and demeton (or their derivatives) may produce effects not seen with all cholinesterase inhibitors. The finding of the scaly tails in the rats on the highest levels of the aged thiolate isomer cannot be explained, but further supports the idea that effects additional to those on cholinesterase may be produced.

\section{Summary}

Aged specimens of the two isomers of demetonmethyl and its sulphoxide are compared with the purified compounds (Heath and Vandekar, 1957) and the effect of storage on the toxic properties of these compounds is illustrated. The effect of dilution in water on the toxic properties of the isomers, as well as commercial "metasystox" is examined.
The great increase in the toxicity of these materials either on storage or after dilution with water was clearly demonstrated by intravenous injections, whereas oral toxicity hardly revealed any change in toxicity. The dependence of the response to the drug on the rate of entry of the inhibitor into the general circulation is discussed.

Chronic feeding experiments were performed on the rats given diets containing 50,100, and 200 p.p.m. of the aged specimen of thiolate isomer or sulphoxide for six months., Brain and erythrocyte cholinesterase activities were strongly inhibited both with the thiolate isomer and sulphoxide; and the degree of inhibition corresponded to the levels fed in the diet. In spite of considerable depression of cholinesterase activity, no signs of poisoning by an anticholinesterase agent in the later stages of experiments were observed. At the highest levels there was some depression of growth in spite of an increased food intake. Scaliness of the tails developed towards the end of the experiment. Anticholinesterase activity of serum in rats after an experiment lasting for six months was moderately pronounced and essentially the same for both compounds.

I wish to thank Dr. D. F. Heath for his collaboration throughout this work and for his help in preparing the account of the chemical changes. I am grateful to Mr. C. R. Kennedy for both valuable technical assistance and for running and keeping the records of the feeding experiments. I also thank Dr. J. M. Barnes and Dr. W. N. Aldridge for their interest in this work and Dr. P. N. Magee for the histological reports.

\section{REFERENCES}

Aldridge, W. N. (1950). Biochem. J., 46, 451.

(1953). Ibid., 54, 442.

, and Barnes, J. M. (1952). Nature (Lond.), 169, 345

Barnes, J. M., and Denz, F. A. (1954). Brit. J. industr. Med., 11, 11 Fukuto, T. R., Metcalf, R. L., March, R. B., and Maxon, M. G. (1955) J. econ. Ent., 48, 347.

Heath, D. F. (1957). Nature (Lond.), 179, 377

二- (1958). J. chem. Soc. 1643. W. W., and Park, P. O. (1955). Philos. Trans. B, 239, 19 i.

239, 191. Dark, P. Lickerish, L. A., and Edson, E. F. (1953). The Park, P. O., Lickerish, L.; A., and Edson, E. F. (1953). The
Composition of "Systox " and the Behaviour of this Insecticide Composition of "Systox" and the Betaviour of this Insect
in the Living Plant. Pest Control Ltd. (Mimeo. report). and Vandekar, M. (1957). Biochem. J., 67, 187.

Mühlmann, R., and Tietz, H. (1956). Höfchen-Briefe [Eng. ed.], 9, 116 Thompson, W. R., and Weil, C. S. (1952). Biometrics., 8, 51.

Vandekar, M. (1957). Nature (Lond.), 179, 154.

, and Heath, D. F. (1957). Biochem. J., 67, 202.

Weil, C. S. (1952). Biometrics, 8, 249.

Wirth, W. (1953). Arch. exp. Path. Pharmak., 217, 144. 